ISSN 0001-6002/2001/43/3/103

Acta Médica Costarricense,(C2001

Colegio de Médicos y Cirujanos

\title{
Esquema de vacunación en Costa Rica
}

Costa Rica ha ido a la vanguardia en el campo de la medicina en comparación con el resto de los países centroamericanos, y el área de las vacunas no ha sido la excepción. Los programas de vacunación introducidos en nuestro país desde la década de los años sesenta han demostrado ser herramientas muy valiosas en la reducción de la mortalidad infantil, como bien se demostró con la introducción de la vacunación contra el heamophilus influenzae en el esquema oficial en 1998. Pero cabe preguntarse, tenemos el esquema ideal de vacunación en Costa Rica?.

Para poder responder a esta pregunta debemos primero preguntarnos, qué es lo ideal?. Si comparamos el esquema de vacunación que hoy se publica en este volumen de Acta Médica con esquemas utilizados en países donde las enfermedades prevenibles por vacunación tienen una incidencia baja o no se presentan, podemos identificar tres puntos que vale la pena analizar. El primero se refiere a la universalidad de los programas de vacunación. Cuando analizamos los datos reportados por el Ministerio de Salud, nos damos cuenta de que si bien es cierto la mayoría de las zonas del país tienen buena cobertura de vacunación, aún existen cantones donde la cobertura no alcanza cifras ideales. Igual de preocupante es el hecho de que aún tenemos el concepto de que "las vacunas son para los niños". Necesitamos concientizar a la población, iniciando por la médica, de que los adultos también tienen que tener sus vacunas completas.

Segundo, estamos aplicando el número idóneo de vacunas? El esquema oficial de vacunación de Costa Rica difiere del utilizado en EEUU, por mencionar un país industrializado, en que no incluye la vacuna conjugada contra neumococo, varicela ni hepatitis A. Preocupa también la diferencia que existe entre la medicina socializada y la medicina privada; es bien conocido que los médicos que practican medicina privada ofrecen una serie de vacunas a sus pacientes que no se ofrecen a los niños y niñas que acuden a consulta de la CCSS o Ministerio de Salud, obviamente por el alto costo de las mismas. Sin embargo, se deben unir esfuerzos para poder conseguir suficiente financiamiento para que toda la población tenga el mismo acceso a todas las vacunas, independientemente de su nivel socioeconómico y permitir que los programas de vacunación sean programas continuos que no corran el riesgo de que sean suspendidos por falta de recursos económicos.

Por último quisiera comentar sobre la calidad de las vacunas. Es bien conocido que existen varias compañías farmacéuticas fabricantes de vacunas, algunas con mejores estándares de calidad que otras. También es bien conocido que la posibilidad de efectos secundarios está en relación con la calidad o tipo del producto. Un ejemplo de esto es el polio asociado a vacunación, el cual se presenta posterior al uso de vacuna de polio oral. Como se discutió en un foro reciente, donde participaron autoridades del Ministerio de Salud, CCSS, INCIENSA, Colegio de Médicos y Cirujanos y Asociación Costarricense de Pediatría debemos analizar si las condiciones epidemiológicas en Costa Rica justifican cambiar, en el esquema oficial de vacunación, la polio oral por la polio parenteral, cuya aplicación no se asocia a polio pos vacunal, para así no solo ofrecer el número ideal de vacunas a nuestros niños sino los productos más seguros y de mejor calidad.

No tenemos la menor duda que en Costa Rica se ha avanzado mucho en lo que a vacunas se refiere, pero las autoridades responsables deben seguir trabajando en conjunto para así lograr el esquema ideal de vacunación para nuestra población.

Arturo Abdelnour Vásquez.

Asistente Servicio de Inmunología

Hospital Nacional de Niños

"Dr. Carlos Sáenz Herrera" 